I N S T I T U T O

$\mathrm{DE}$

M E D I C I N A

T R O P I C A L

DE

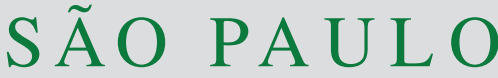

JOURNAL OF THE SÃO PAULO INSTITUTE OF TROPICAL MEDICINE

'Universidade Estadual de Maringá, Programa de Pós-Graduação em Biociências e Fisiopatologia, Maringá, Paraná, Brazil

'Universidade Estadual de Maringá, Programa de Pós-Graduação em Ciências da Saúde, Maringá, Paraná, Brazil

'Universidade Estadual de Maringá, Departamento de Análises Clínicas e Biomedicina, Maringá, Paraná, Brazil

Correspondence to: Jully Oyama Universidade Estadual de Maringá, Programa de Pós-Graduação em Ciências da Saúde, Avenida Colombo, 5790, Jardim Universitário, CEP 87020-900, Maringá, PR, Brazil

Tel: +55 44 3011-4878, +55 44 3011-4848

E-mail: jully_oyama@yahoo.com.br

Received: 22 June 2017

Accepted: 28 November 2017
http://dx.doi.org/10.1590/S1678-9946201860003

\section{American tegumentary leishmaniasis: diagnostic and treatment challenges in a clinical case}

Jully Oyama', Fabiana Borges Padilha Ferreira², Carolina Cella Conter ${ }^{2}$, Daniele Stéfanie Sara Lopes Lera-Nonose ${ }^{2}$, Áquila Carolina Fernandes Herculano Ramos-Milaré ${ }^{2}$, Eneide Aparecida Sabaini Venazzi ${ }^{3}$, Thaís Gomes Verzignassi Silveira ${ }^{3}$, Maria Valdrinez Campana Lonardoni ${ }^{3}$

\section{ABSTRACT}

This clinical case presents a patient with a raised and ulcerative lesion with erythematous edges in the mouth, on the lower lip that was unsuccessfully treated as herpes labialis. Clinical data and laboratory tests (Montenegro skin test, indirect immunofluorescence, direct parasite search and polymerase chain reaction) led to the diagnosis of American tegumentary leishmaniasis caused by Leishmania (Viannia) sp. Treatment with pentavalent antimonial (Glucantime $^{\circledR}$ ) for 120 days was not effective and administration of amphotericin B for 30 days resulted in wound healing. Glucantime ${ }^{\circledR}$ treatment protocol was longer than the recommended by the Brazilian Ministry of Health in the handbook of mucosal leishmaniasis. This suggests that amphotericin B should have been administered earlier, preventing the psychological and social problems faced by the patient. This study reports a rare clinical case of primary mucosal leishmaniasis on the lip that had a delayed diagnosis, highlighting the precariousness in the management of disease and showing that, despite the importance of leishmaniasis in Brazil, it is still neglected by health professionals.

KEYWORDS: Leishmania. Leishmaniasis.

\section{INTRODUCTION}

Leishmaniasis is a parasitic disease caused by protozoa of the genus Leishmania sp., transmitted by the bite of naturally infected sandflies of the genus Lutzomyia. American tegumentary leishmaniasis (ATL) is the most common form of disease and it is manifested as cutaneous and mucosal leishmaniasis. These lead to serious clinical manifestations, being the mucosal form the worse one because it affects sites such as nose and mouth, leading to permanent scars, disfigurements and, in some cases, debilitations with strong psychological involvement ${ }^{1}$. This form is usually secondary to the cutaneous one when it is not correctly treated or is lef untreated, but, in rare cases, it can be primary ${ }^{2}$. In comparison with other mucosal sites, the mouth has a shorter evolution time ${ }^{3}$.

Leishmaniasis is endemic in 98 countries with more than 350 million people exposed to the risk and an estimated incidence of one and a half million new cases per year of cutaneous leishmaniasis. ATL is a major public health problem in the New World and it is a challenge for leishmaniasis endemic countries 4 .

Leishmaniasis treatment shows several limitations due to problems related to serious side effects caused by first-choice drugs, pentavalent antimonial (Glucantime ${ }^{\circledR}$ ), high toxicity of the second-choice drugs (amphotericin B), in 
addition, there are still therapeutic failure, emergence of resistant parasite strains, daily parenteral treatment, high number of patients that discontinue treatment and insufficient amount of drugs in endemic areas ${ }^{1}$. Differences between treatment of cutaneous and mucosal forms are basically the time and drug concentration, being longer and higher in the latter ${ }^{2}$. Clinical and laboratory monitoring of patients, including electrocardiogram, is recommended at a minimum interval of 10 days during treatment and 30 days after treatment. Laboratory monitoring should include serum levels of urea, creatinine, glucose, electrolytes, hepatic and pancreatic enzymes ${ }^{5,6}$.

The aim of this study was to report a rare clinical case of primary mucosal leishmaniasis on the lip that had a delayed diagnosis, highlighting the precariousness in the disease management. In this case, there was also a therapeutic failure in the first choice of treatment, which is common, but still important.

\section{CASE REPORT}

A twenty-five-year-old male patient from Paiçandu, Paraná, sought the health care unit of his city because of an ulcer on the lower lip that was treated as herpes labialis without wound healing or improvement. In August 2015, after thirty days of the ulcer appearance, the patient was referred to the LEPAC (Laboratório de Ensino e Pesquisa em Análises Clínicas) at the Universidade Estadual de
Maringá. During examination of the lower lip, an ulcerated lesion was observed, it was erythematous with raised edges and there was the presence of granulomatous, purulent and crusty contents characteristic of mucosal leishmaniasis (Figure 1A). In a patient interview, he described that he frequently fished in the Ivai river, an endemic region for Leishmania (Viannia) sp. and several acquaintances acquired leishmaniasis in the same place ${ }^{2}$.

The conducted laboratory tests were Montenegro skin test, direct parasite search in the scraping from lesion edges and in the patient's blood sample an indirect immunofluorescence for anti-Leishmania IgG antibodies was performed. The Montenegro skin test was reactive with an induration of $6 \mathrm{~mm}$ in diameter, indirect immunofluorescence was positive for anti-Leishmania IgG antibodies with titer of 1:80 and the direct parasite search was also positive (Figure 1B). Detection of the parasite in the scraping from lesion edges and in the patient's blood sample were made by polymerase chain reaction (PCR) using primers to amplify a 70-bp fragment of the kinetoplast minicircle DNA (kDNA) from parasites belonging to Leishmania (Viannia) sp. subgenera. Only the scraping material was positive (Figure 1C).

The initial therapeutic regimen for treating leishmaniasis was Glucantime ${ }^{\circledR}$, three ampoules per day $(1.215 \mathrm{mg})$ with four cycles of treatment: 20 and 30 days with an interval of 12 weeks, and two extra-cycles of 40 and 30 days with a break of approximately 10 days. This therapeutic scheme

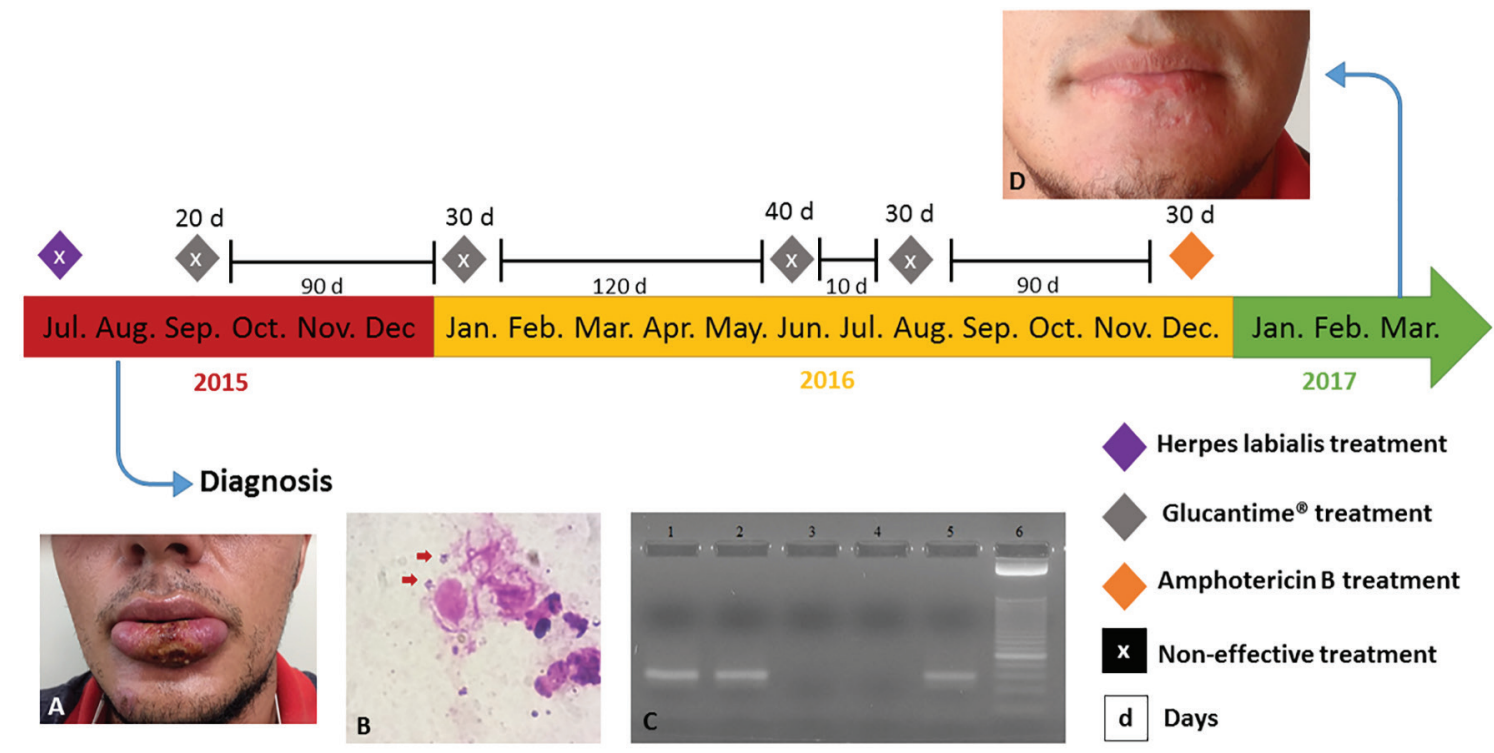

Figure 1 - Patient's clinical history: A) Lesion on the lower lip at the time of leishmaniasis diagnosis (one-month-old); B) Direct search of parasite in the material obtained by scraping of the lesion, stained by Giemsa; C) Polymerase chain reaction (PCR) showing the 70-bp fragment of the kinetoplast minicircle DNA (kDNA) from subgenera Leishmania (Viannia) sp.; lane 1: the patient's lesion sample; lane 2: positive control [DNA from blood sample containing $5 \times 10^{-3}$ promastigotes of Leishmania (Viannia) braziliensis]; lane 3: the patient's blood sample; lane 4: negative control (sterile water); lane 5: positive control [DNA from promastigotes of Leishmania (Viannia) braziliensis]; lane 6: molecular weight marker 25-bp ladder; D) Patient after treatment with amphotericin B (19 months after correct diagnosis) 
used by the patient is actually the one recommended to cutaneous leishmaniasis, since, according to what is suggested by the Brazilian Ministry of Health, the duration of the first cycle is 20 days with $10-20 \mathrm{mg} / \mathrm{kg} /$ day of Glucantime $^{\circledast}$, respecting the limit of three ampoules per day, being repeated for more 30 days in case of failure with an interval of 12 weeks ${ }^{2}$. At this stage, the patient was followed up by a new medical team, who decided not to use the therapeutic regimen recommended by the Ministry of Health, prescribing other two cycles of Glucantime ${ }^{\circledR}$, 40 and 30 days with an interval of approximately 10 days between them. The treatment with Glucantime ${ }^{\circledR}$ was unsuccessful, because the lesion reappeared with nodular aspect followed by ulceration. The side effects reported by the patient were present only on the first day of Glucantime ${ }^{\circledR}$ administration (seasickness and fever). Electrocardiogram was used to monitor the treatment side effects. In this situation, amphotericin B administration was necessary and $1 \mathrm{mg} / \mathrm{kg} /$ day was administered during 30 days with an interval of three days every 10 days, respecting the maximum of $50 \mathrm{mg}$ (one flask) per administration.

Delayed diagnosis and treatment failure led the patient to episodes of depression. In March 2017, three months after treatment with amphotericin B and 19 months after correct diagnosis, the patient was in remission and under observation (Figure 1D). The project received the approval of the Project Management System (process No 1505/1997) of the Universidade Estadual de Maringá and the patient signed an informed consent form and a photograph consent form.

\section{DISCUSSION}

This report describes an atypical case of ATL due to the clinical presentation (primary mucosal form) on the lower lip. The ulcer was treated as herpes labialis and, for appropriate treatment, an accurate diagnosis is necessary involving anamnesis, lesion characteristics, laboratory tests and epidemiological data of the region ${ }^{1}$.

According to Gomes et al. ${ }^{7}$, the multidisciplinary approach for differentiation among several diagnostic possibilities is incredibly important to plan and end therapy, avoiding lesion disfigurements. In this case report, there was a delay, and failure in the diagnosis leading to lesion worsening, evidencing the negligence of the disease by health professionals. The Brazilian Ministry of Health suggests in the ATL handbook, a primary treatment for mucosal form with Glucantime ${ }^{\circledR} 20 \mathrm{mg} / \mathrm{kg} /$ day for 30 days, repeated after 12 weeks, if not efficient for more 30 days, totaling 60 days of therapy ${ }^{2}$. If the symptoms remain, the second-choice drug must be used ${ }^{1,2}$.
This disagreement in the treatment schedule could have been caused by the lesion site, which was in the transition of the cutaneous (lower base of the lip) and the mucosal (lip) tissue. Another important point in the treatment was the interval among treatment cycles, which was shorter than recommended, based on the fact that Glucantime $^{\circledast}$ is a deposit drug with therapeutic effects even after treatment ${ }^{6}$. The change of the medical team that was following up the patient shows a still deficient facet of health services in the region. The two extra-cycles to which the patient was submitted resulted in therapeutic failure, probable resistance of the parasite strain and a delay of amphotericin B administration. After amphotericin B administration, there was a complete wound healing and the patient continued to be monitored because clinical cure is established after one year after remission. The long time elapsed since the lesion appearance, correct diagnosis and wound healing (19 months), associated with the ulcer site and the need of outpatient care in primary health care or hospital facilities for the administration of Glucantime $^{\circledR}$ and amphotericin B, respectively, led the patient to depression episodes with reflex in his social and professional life.

According to Satilho et $a l .^{8}$, ATL is a disease with serious clinical manifestations that impacts the patient's appearance, resulting in prejudice and consequently social exclusion, affecting the patient's psychology in the social and economic field. Another important point is the need for pharmacological monitoring with several laboratory tests, not just the electrocardiogram as it was performed in the follow-up of this patient. These tests are extremely important for monitoring side effects and preventing toxicity of drugs used in leishmaniasis treatment, keeping the patient's welfare. In front of this case report, it is clear that the long time elapsed between the lesion appearance and its healing affects the patient outcomes showing that, despite the importance of leishmaniasis in Brazil, it is still neglected by health professionals.

\section{REFERENCES}

1. Gontijo B, Carvalho ML. Leishmaniose tegumentar americana. Rev Soc Bras Med Trop. 2003;36:71-80.

2. Brasil. Ministério da Saúde. Secretaria de Vigilância em Saúde. Departamento de Vigilância das Doenças Transmissíveis. Manual de vigilância da leishmaniose tegumentar. Brasília: Ministério da Saúde; 2017.

3. Costa DC, Palmeiro MR, Moreira JS, Martins AC, Silva AF, Madeira MF, Quintella LP, et al. Oral Manifestations in the American Tegumentary Leishmaniasis. PLoS One. 2014;9:e109790. 
4. World Health Organization. Control of leishmaniases: report of a meeting of the WHO Expert Committee on the Control of Leishmaniases, Geneva, 22-26 March 2010. Geneva: WHO; 2010.

5. Oliveira LF, Schubach AO, Martins MM, Passos SL, Oliveira RV, Marzochi MC, et al. Systematic review of the adverse effects of cutaneous leishmaniasis treatment in the New World. Acta Trop. 2011;118:87-96.
6. GLUCANTIME ${ }^{\circledR}$ (antimoniato de meglumina). [package insert]. São Paulo: Sanofi-Aventis Farmacêutica; 2017.

7. Gomes AC, Silva ED, Pita Neto IC, Bezerra TP. Leishmaniose muco-cutânea: relato de caso clínico. Rev Cir Traumatol BucoMaxilo-Fac. 2004;4:223-8.

8. Satilho KL, Silva DG, Oliveira DU, Uesugui HM. Leishmaniose tegumentar americana: as ações profiláticas do profissional enfermeiro. Rev Cient Fac Educ Meio Ambiente. 2012;3:22-38. 